\title{
Neutron activation analysis on sediments from Victoria Land, Antarctica: multi-elemental characterization of potential atmospheric dust sources
}

\author{
G. Baccolo $\cdot$ C. Baroni $\cdot$ M. Clemenza $\cdot$ \\ B. Delmonte $\cdot$ V. Maggi $\cdot$ A. Motta $\cdot$ \\ M. Nastasi $\cdot$ E. Previtali $\cdot$ M. C. Salvatore
}

Received: 11 September 2013/Published online: 20 November 2013

(C) Akadémiai Kiadó, Budapest, Hungary 2013

\begin{abstract}
The elemental composition of 40 samples of mineral sediments collected in Victoria Land, Antarctica, in correspondence of ice-free sites, is presented. Concentration of 36 elements was determined by instrumental neutron activation analysis, INAA. The selection of 6 standard reference materials and the development of a specific analytical procedure allowed to reduce measurements uncertainties and to verify the reproducibility of the results. The decision to analyze sediment samples from Victoria Land ice-free areas is related to recent investigations regarding mineral dust content in the TALos Dome ICE core $\left(159^{\circ} 11^{\prime} \mathrm{E} ; 72^{\circ} 49^{\prime} \mathrm{S}\right.$, East Antarctica, Victoria Land), in which a coarse local fraction of dust was recognized. The characterization of Antarctic potential source areas of atmospheric mineral dust is the first step to identify the active sources of dust for the Talos Dome area and to reconstruct the atmospheric pathways followed by air masses in this region during different climatic periods.
\end{abstract}

G. Baccolo $\cdot$ B. Delmonte $\cdot$ V. Maggi

Dipartimento di Scienze, Ambiente e Territorio e Scienze della

Terra, University of Milano-Bicocca, Milan, Italy

G. Baccolo $\cdot$ M. Clemenza ( $\square) \cdot$ V. Maggi $\cdot$ A. Motta ·

M. Nastasi · E. Previtali

INFN, Sezione di Milano-Bicocca, Milan, Italy

e-mail: massimiliano.clemenza@mib.infn.it

C. Baroni - M. C. Salvatore

Dipartimento di Scienze della Terra, University of Pisa, Pisa, Italy

C. Baroni

CNR, Istituto di Geoscienze e Georisorse, Pisa, Italy

M. Clemenza · A. Motta · M. Nastasi · E. Previtali Dipartimento di Fisica, University of Milano-Bicocca, Milan, Italy
Principal components analysis was used to identify elements and samples correlations; attention was paid specially to rare earth elements (REE) and incompatible/ compatible elements (ICE) in respect to iron, which proved to be the most discriminating elemental groups. The analysis of REE and ICE concentration profiles supported evidences of chemical weathering in ice-free areas of Victoria Land, whereas cold and dry climate conditions of the Talos Dome area and in general of East Antarctica.

Keywords INAA - Gamma spectrometry ·

Antartica - Ice core - Atmospheric dust sources .

Multivariate analysis $\cdot$ PCA $\cdot$ REE $\cdot$ ICE

\section{Introduction}

Atmospheric mineral dust and climate are deeply linked: climate changes modify production, transport and depositional processes of dust on different timescales, but dust itself affects the climate, both directly and indirectly [1]. Climate archives, such as ice cores from polar regions, revealed that Aeolian dust is a key proxy for past climate variability [2]. Physical and chemical properties of mineral aerosol in ice cores provide information about past atmospheric circulation and paleo-environmental conditions at the sources [3-5]. In this context one of the most important scientific goal, concerns dust origin and source tracking, which is essentially carried out by comparing the geochemical, mineralogical and microphysical properties of available material at the source areas with dust particles entrapped in the cores [6].

This work stems from the need to track dust sources at Talos Dome $\left(159^{\circ} 11^{\prime} \mathrm{E} ; 72^{\circ} 49^{\prime} \mathrm{S}\right)$, where a 250 kyr-old ice core was drilled in the framework of the TALos Dome ICE 


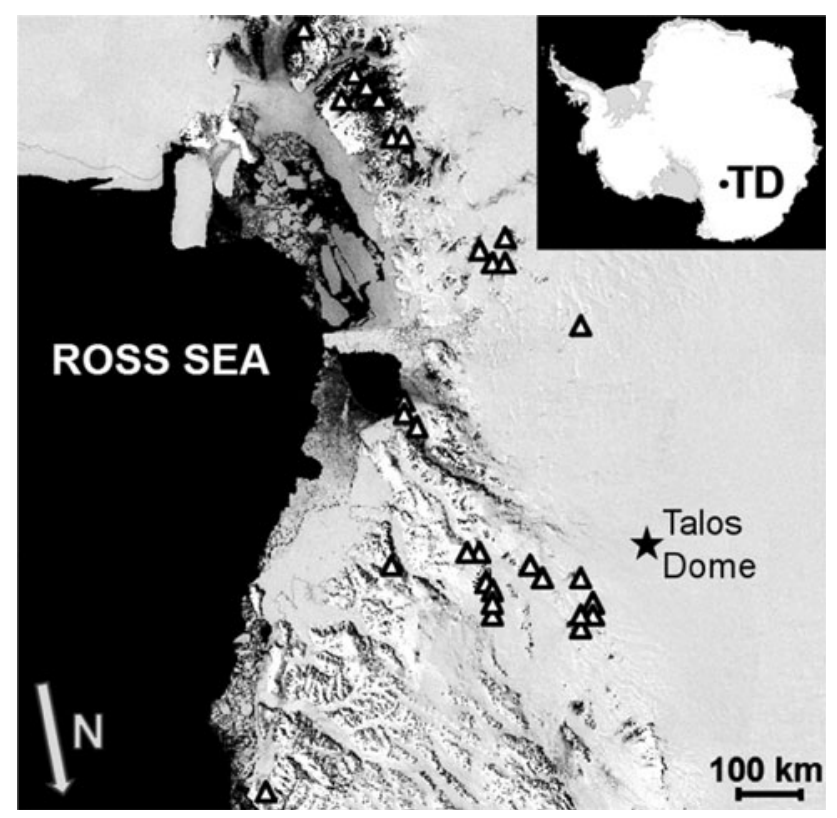

Fig. 1 Satellite image (Landsat image mosaic of Antarctica project) of Victoria Land. Triangles represent the sample collection sites, the black star stands for Talos Dome, where TALDICE ice core was drilled

(TALDICE) core drilling project [7]. Isotopic [8], magnetic [9], microphysical and meteorological $[10,11]$ evidences point towards a contribution of proximal high-altitude dust sources of Victoria Land, that is likely mixed with dust originating from the remote areas of the Southern Hemisphere and with volcanic material probably remobilized from different volcanic sources [11].

In order to characterize the elemental composition of Antarctic PSA samples the elemental composition of 40 "bulk" $(\varnothing<1 \mathrm{~mm})$ sediment samples from Victoria Land was determined, opting for INAA technique because it allows the determination of several elements in parallel, ranging from the major elements to trace ones. Among the different techniques usually adopted for multi-elemental characterizations, as ICP-MS (inductively coupled plasma mass spectrometry, [12]), PIXE or XRF (particle induced $\mathrm{X}$-ray emission, $\mathrm{X}$-ray fluorescence, [13]), INAA requires a reasonably reduced amount of sediment $(<250 \mathrm{mg})$ for the detection of several elements with very different concentrations without any sample dissolution or dilution. Due to these important features INAA is one of the most common techniques for the determination of the elemental composition in geological samples [14-18].

Samples description

Geological, geographical and geomorphological features of samples are presented in previous studies [8, 11]; they are incoherent mineral sediments collected in the Victoria
Land, Antarctica (Fig. 1), which are potentially subjected to Aeolian deflation. In this work we focused attention on the bulk fraction of these samples $(\varnothing<1 \mathrm{~mm})$, with the future perspective to compare these data with those obtained by the analysis on the fine-grained fraction that can be transported by air masses for long distances $(\varnothing<10-20 \mu \mathrm{m})$. Samples can be divided in regoliths (incoherent material produced by mechanical and physical weathering of parental rock types, 25 samples), Quaternary glacial deposits (7 samples), Aeolian sediments that were already subjected to mobilization and transport by wind and which have been retrieved mostly in Aeolian sediment traps ( 5 samples), sand from coastal beaches ( 2 samples) and sand from a lacustrine area (1 sample). From a lithological point of view most samples have a mixed composition, which is related not only to the complex geological history of the Transantarctic Mountains [19] but also to the nature of the selected deposits; for a more comprehensive description of the samples, we remind to $[8,11]$.

\section{Experimental}

INAA can be performed applying different analytical methods: relative and k-0 (for a complete review see [20]). It was decided to apply the relative method, using different standard reference materials (SRM). According to this technique the analysis is carried out comparing the radioactive activity of the irradiated samples to the one of the SRM's, whose elemental composition is known. The calculations associated to this method are simplified, since it is not necessary to know neutron flux, neutron capture cross sections, branching ratios and detector efficiencies [21]; also uncertainties are reduced because errors related to these quantities are neglected. 6 Standard Reference Materials (SRM) were selected: NIST (National Institute of Standards and Technology) SRM 1645 (river sediments), NIST SRM 2704 (Buffalo River sediments), NIST SRM 2709a (San Joaquin soil), NIST SRM 2710a (Montana Soil), USGS (U.S. Geological Survey) AGV2 (powdered andesite), USGS BCR2 (powdered basalt). These standards cover 70 elements and most of them are certified in more than one standard. The 2 rock powder SRMs were selected because andesite and basalt are rocks quite similar to many samples.

Sample preparation, irradiation and counting

Sample irradiations were performed at LENA (Laboratory of Applied Nuclear Energy) in Pavia where it is installed a $250 \mathrm{~kW}$ TRIGA Mark II nuclear reactor with 4 different irradiation channel facilities: CENTRAL, LAZY SUSAN, RABBIT and THERMAL [22]. To maximize the number 
Table 1 Main information regarding irradiations and acquisitions. Irradiation times, neutron fluxes, cooling times are reported. In the last column the observed elements, divided considering the different acquisitions, are listed

\begin{tabular}{|c|c|c|c|c|c|c|c|}
\hline Irradiation & $\begin{array}{l}\text { Average } \\
\text { sample } \\
\text { mass (mg) }\end{array}$ & $\begin{array}{l}\text { Neutron flux } \\
\left(\mathrm{n} \mathrm{cm}^{-2} \mathrm{~s}^{-1}\right)\end{array}$ & $\begin{array}{l}\text { Irradiation } \\
\text { time }\end{array}$ & $\begin{array}{l}\text { Number of } \\
\text { acquisitions }\end{array}$ & $\begin{array}{l}\text { Cooling } \\
\text { time }\end{array}$ & $\begin{array}{l}\text { Acquisition } \\
\text { time (s) }\end{array}$ & Obs. elements \\
\hline $\begin{array}{l}\text { Short } \\
\text { irradiation }\end{array}$ & 100 & $7 \times 10^{12}$ & $60 \mathrm{~s}$ & 1 & $300-720 \mathrm{~s}$ & 300 & $\mathrm{Na}, \mathrm{Mg}, \mathrm{Al}, \mathrm{Cl}, \mathrm{Ca}, \mathrm{Ti}, \mathrm{V}, \mathrm{Mn}, \mathrm{Cu}, \mathrm{I}, \mathrm{Ba}$ \\
\hline \multirow{4}{*}{$\begin{array}{l}\text { Long } \\
\text { irradiation }\end{array}$} & 200 & $2 \times 10^{12}$ & $18 \mathrm{~h}$ & 4 & $3-4$ days & 150 & $\mathrm{Na}, \mathrm{K}, \mathrm{Sc}, \mathrm{Cr}, \mathrm{Fe}, \mathrm{As}, \mathrm{Br}, \mathrm{Sb}, \mathrm{La}, \mathrm{Sm}, \mathrm{W}$ \\
\hline & & & & & 4-6 days & 1,000 & $\begin{array}{l}\mathrm{Na}, \mathrm{Sc}, \mathrm{Ca}, \mathrm{Cr}, \mathrm{Fe}, \mathrm{Co}, \mathrm{As}, \mathrm{Br}, \mathrm{Rb}, \mathrm{Mo} \\
\mathrm{Sb}, \mathrm{Ba}, \mathrm{Cs}, \mathrm{La}, \mathrm{Ce}, \mathrm{Sm}, \mathrm{Nd}, \mathrm{Tb}, \mathrm{Ho}, \mathrm{Tm} \\
\text { Yb, Lu, Hf, W, Au, Th, U }\end{array}$ \\
\hline & & & & & $7-13$ days & 10,000 & $\begin{array}{l}\mathrm{Na}, \mathrm{Sc}, \mathrm{Ca}, \mathrm{Cr}, \mathrm{Fe}, \mathrm{Ni}, \mathrm{Co}, \mathrm{Zn}, \mathrm{Sr}, \mathrm{Rb}, \mathrm{Zr} \\
\mathrm{Ag}, \mathrm{Sb}, \mathrm{Cs}, \mathrm{La}, \mathrm{Ce}, \mathrm{Nd}, \mathrm{Eu}, \mathrm{Tb}, \mathrm{Tm}, \mathrm{Yb} \\
\mathrm{Lu}, \mathrm{Hf}, \mathrm{Ta}, \mathrm{Th}\end{array}$ \\
\hline & & & & & $35-160$ days & 50,000 & $\begin{array}{l}\mathrm{Sc}, \mathrm{Cr}, \mathrm{Fe}, \mathrm{Co} \mathrm{Ni}, \mathrm{Zn}, \mathrm{Sr}, \mathrm{Zr}, \mathrm{Sn}, \mathrm{Sb}, \mathrm{Cs}, \\
\text { Ce, Eu, Tb, Tm, Hf, Lu, Ta, Hg }\end{array}$ \\
\hline
\end{tabular}

of detectable elements it was decided to perform two irradiations, one to observe short-lived radionuclides, the second one to observe medium- and long-lived radionuclides (see Table 1). Before the irradiation all the samples were dry-sieved using a $1 \mathrm{~mm}$ sieve in order to make them homogenous and comparable. After this passage every sample was weighted and arranged in polyethylene vials (volume of $1 \mathrm{ml}$ ), previously cleaned with a solution of hyper-pure nitric acid $2 \%$ mass concentration.

Different $\gamma$-detectors were selected to measure irradiated samples. For the samples irradiated during the short irradiation an ORTEC HpGe detector was used. This detector is a coaxial p-type low background one used also for environmental radioactivity monitoring [22]. The relative detection efficiency is $30 \%$ and the energy resolution at the $1,332 \mathrm{keV}$ gamma line of ${ }^{60} \mathrm{Co}$ is $1.8 \mathrm{keV}$ Full Width Half Maximum (FWHM). For the samples irradiated during the long irradiation two HpGe detectors were used. The acquisition of $150 \mathrm{~s}$ was performed using the same $\mathrm{HpGe}$ used for the RABBIT irradiation, the other $\gamma$-rays acquisitions $(1,000,10,000$ and 50,000 s) were done using an ORTEC well-detector HpGe (GWL series) with a total active volume of $350 \mathrm{~cm}^{3}$. Thanks to the geometric structure of the detector a near $4 \pi$ geometry is reached by the Ge crystal, providing the maximum absolute counting efficiency available. The energy resolution at the $1,332 \mathrm{MeV}$ gamma line of ${ }^{60} \mathrm{Co}$ is $2.2 \mathrm{keV}$ FWHM.

\section{Calculations}

The determination of element concentrations was realized comparing samples and SRMs $\gamma$-ray activities, taking into account the different cooling and acquisition times. The integral areas defined by the observed photo-peaks were determined through a Gaussian function, after the subtraction of the underlying radioactive background, which was fitted using the most proper polynomial function. These passages were carried out using the TASSO software, developed for the analysis of energy spectra [23].

The uncertainties associated to the concentrations were calculated considering 4 different sources of error: instrumental error of the scale used for weighing samples; error associated to the certified concentrations of SRMs, statistical errors linked to the instrumental number of counts and to the extent of the radioactive background; the errors related to the Gaussian Fit. For that elements whose associated peaks were not observed in the $\gamma$-spectra of the samples, concentrations couldn't be determined; in these cases upper limits of concentration (UC) were calculated. These limits correspond to three time the standard deviation of the radioactive background (confidence level of $99.7 \%)$.

Since lot of elements were analyzed in more than one acquisition, using different photo-peaks and in some cases different isotopes too, final concentrations were determined with a weighted average defining the inverse square of measure uncertainties as weight.

\section{Results}

Analysis of SRMs relative specific activities

Particular attention was paid to the stability of relative specific activities of SRMs; quantitative INAA analysis is based on this parameter which links standards to samples, allowing the measurement. A precise determination of relative standard specific activity is essential to achieve good quality results. Its stability depends on several parameters: at first temporal and spatial neutron flux stability during the 
Table 2 Blank contaminations; these values were determined combining both irradiations and all acquisitions

\begin{tabular}{lc}
\hline Element & Contamination \\
\hline $\mathrm{Al}$ & $0.50 \pm 0.07 \mu \mathrm{g}$ \\
$\mathrm{Ca}$ & $10 \pm 2 \mu \mathrm{g}$ \\
$\mathrm{Co}$ & $0.38 \pm 0.05 \mathrm{ng}$ \\
$\mathrm{Cr}$ & $30 \pm 5 \mathrm{ng}$ \\
$\mathrm{Na}$ & $0.22 \pm 0.06 \mu \mathrm{g}$ \\
$\mathrm{Sc}$ & $10 \pm 2 \mathrm{ng}$ \\
$\mathrm{Ta}$ & $3.8 \pm 0.8 \mathrm{ng}$ \\
$\mathrm{Zn}$ & $162 \pm 9 \mathrm{ng}$ \\
\hline
\end{tabular}

irradiation, but also other ones like the sample position in respect to the detector, sample shape and self-adsorption of neutrons. Using different SRMs it was possible to monitor all these parameters and to determine if measurements were performed under the same conditions, assessing measurements reproducibility. Comparing the relative specific activities obtained from different standards and from different aliquots of the same SRM it was possible to verify this point. Standard deviations associated to the relative specific activities were always lower than $20 \%$ for all the considered $\gamma$-energies.

The use of several SRMs was useful not only to monitor measurements reproducibility, but also to reduce measurements uncertainties. Using more than one SRM it is possible to calculate the weighted average relative specific activities. This allowed to reduce the errors associated to the count rate fluctuations by a factor up to 5 .

Elements observation and quantification

Gamma rays analysis allowed the observation of 11 elements for short-irradiated aliquots and 37 elements for long-irradiated ones; since 3 elements were recognized in both aliquots, a total of 45 elements were observed. For a complete list of the observed elements see Table 1. Quantification of these elements wasn't successful for all of them, some elements were discarded because they were observed in only few samples (in less than $50 \%$ of the total). The rejected elements are: $\mathrm{Cl}, \mathrm{Cu}, \mathrm{Br}, \mathrm{Mo}, \mathrm{Ag}, \mathrm{I}, \mathrm{Ho}$, $\mathrm{W}, \mathrm{Au}$; all the remaining 36 elements were quantified. Since blank analysis revealed the presence of contaminations in empty vials (Table 2), blank contaminations were subtracted to sample analytical signal. The determined elements are: $\mathrm{Na}, \mathrm{Mg}, \mathrm{Al}, \mathrm{K}, \mathrm{Ca}, \mathrm{Sc}, \mathrm{Ti}, \mathrm{V}, \mathrm{Cr}, \mathrm{Mn}, \mathrm{Fe}, \mathrm{Co}$, $\mathrm{Ni}, \mathrm{Zn}, \mathrm{As}, \mathrm{Rb}, \mathrm{Sr}, \mathrm{Zr}, \mathrm{Sn}, \mathrm{Sb}, \mathrm{Cs}, \mathrm{Ba}, \mathrm{La}, \mathrm{Ce}, \mathrm{Nd}, \mathrm{Sm}, \mathrm{Eu}$, $\mathrm{Tb}, \mathrm{Tm}, \mathrm{Yb}, \mathrm{Lu}, \mathrm{Hf}, \mathrm{Ta}, \mathrm{Hg}$, Th, U. The elements range from major elements which constitute more than $1 \%$ each of total samples weight, to trace elements. Concentrations span more than 5 orders of magnitude, as shown in Table 3, where the average concentration and the average relative error of each element are reported.
Table 3 List of the determined elements; average concentrations and average relative uncertainties are reported

\begin{tabular}{|c|c|c|}
\hline Element & $\begin{array}{l}\text { Average } \\
\text { concentration }(\mathrm{ppm})\end{array}$ & $\begin{array}{l}\text { Average relative } \\
\text { uncertainty }(\%)\end{array}$ \\
\hline $\mathrm{Na}$ & 17,200 & 2.36 \\
\hline $\mathrm{Mg}$ & 15,500 & 5.32 \\
\hline $\mathrm{Al}$ & 68,000 & 4.00 \\
\hline $\mathrm{K}$ & 19,000 & 18.16 \\
\hline $\mathrm{Ca}$ & 33,000 & 3.92 \\
\hline $\mathrm{Sc}$ & 21.4 & 3.87 \\
\hline $\mathrm{Ti}$ & 4,600 & 15.81 \\
\hline $\mathrm{V}$ & 130 & 11.26 \\
\hline $\mathrm{Cr}$ & 60 & 5.78 \\
\hline $\mathrm{Mn}$ & 980 & 3.56 \\
\hline $\mathrm{Fe}$ & 52,400 & 1.45 \\
\hline $\mathrm{Co}$ & 25.3 & 3.51 \\
\hline $\mathrm{Ni}$ & 40 & 12.18 \\
\hline $\mathrm{Zn}$ & 126 & 4.16 \\
\hline As & 2.81 & 19.60 \\
\hline $\mathrm{Rb}$ & 157 & 5.23 \\
\hline $\mathrm{Sr}$ & 130 & 10.40 \\
\hline $\mathrm{Zr}$ & 164 & 10.47 \\
\hline $\mathrm{Sn}$ & 17 & 13.00 \\
\hline $\mathrm{Sb}$ & 0.40 & 16.75 \\
\hline $\mathrm{Cs}$ & 9.4 & 3.92 \\
\hline $\mathrm{Ba}$ & 410 & 4.45 \\
\hline $\mathrm{La}$ & 36.5 & 1.88 \\
\hline $\mathrm{Ce}$ & 72 & 2.93 \\
\hline $\mathrm{Nd}$ & 31 & 10.46 \\
\hline $\mathrm{Sm}$ & 6.5 & 6.83 \\
\hline $\mathrm{Eu}$ & 1.01 & 2.09 \\
\hline $\mathrm{Tb}$ & 0.94 & 2.15 \\
\hline $\mathrm{Tm}$ & 0.39 & 8.52 \\
\hline $\mathrm{Yb}$ & 3.1 & 4.50 \\
\hline $\mathrm{Lu}$ & 0.51 & 6.09 \\
\hline Hf & 5.6 & 3.69 \\
\hline $\mathrm{Ta}$ & 5.2 & 2.63 \\
\hline $\mathrm{Hg}$ & 0.30 & 14.72 \\
\hline $\mathrm{Th}$ & 13.7 & 3.88 \\
\hline $\mathrm{U}$ & 4.5 & 12.40 \\
\hline
\end{tabular}

Average concentrations span from $0.30 \mathrm{ppm}$ for $\mathrm{Hg}$ to $68,000 \mathrm{ppm}$ for Al. Elements to which is associated a relative uncertainties exceeding $15 \%$ (relatively to the average concentration) are $\mathrm{K}$, Ti, As and $\mathrm{Sb} . \mathrm{K}$ and $\mathrm{Ti}$ are some of those elements which were determined using only one $\gamma$-energy in one acquisition; $\mathrm{As}$ and $\mathrm{Sb}$ are very rare elements in earth crust and their concentrations are near the detection limits; for these reasons uncertainties were higher than $15 \%$

Geochemistry

A preliminary data interpretation is now presented. In order to explore variables and samples correlations a principal 
Fig. 2 Scree-plot of PCA: explained variance $(\%)$ associated to the first 10 principal components is reported. The first and the second components are the most important; a significative step between the second and the third components can be observed

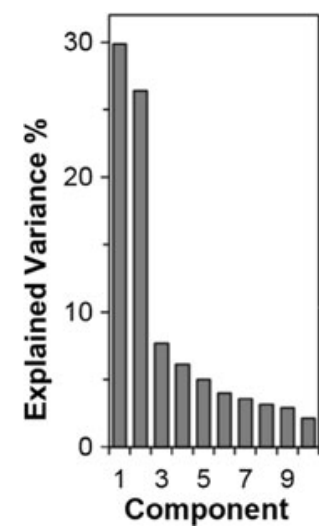

component analysis (PCA, [24]) was carried out. This statistical method was chosen because it allows to identify variables correlations and to describe samples in a multivariate way, considering at the same time all the defined variables. The analysis of PCA revealed that the first 10 principal components explain more than $90 \%$ of the total variance of our data, in particular the first one explains $30 \%$ and the second one $26 \%$ (Fig. 2). Attention was paid to the first 2 principal components (PC1 and PC2), which explained $56 \%$ of the total variance of data; it is clear from Fig. 2 that the first two components are the most important; the other ones can be neglected because a significative step between the second component and the third one, which reveals a change in data structure, is present. Loading plot relative to $\mathrm{PC} 1$ and $\mathrm{PC} 2$ is represented in Fig. 3; PC1 is clearly related to rare earth element content: $\mathrm{La}, \mathrm{Ce}, \mathrm{Nd}$, $\mathrm{Sm}, \mathrm{Tb}, \mathrm{Eu}, \mathrm{Yb}, \mathrm{Tm}$ and $\mathrm{Lu}$ (the REEs determined in samples) occupy the right side of the graph, where PC1 is positive. PC2 is associated to another important geochemical feature: the content of incompatible and compatible elements (ICE). In geochemistry compatibility/ incompatibility is related to the geochemical behavior of elements in respect to iron [25]. Compatible elements show geochemical properties similar to iron ones and they are found in the same minerals, the opposite behavior is followed by incompatible elements and it is difficult to find them associated to iron minerals. In Fig. 3 compatible elements occupy the lower part of the graph, where iron is placed; these elements are (from bottom to top): $\mathrm{Co}, \mathrm{Sc}, \mathrm{V}$, $\mathrm{Mg}, \mathrm{Mn}, \mathrm{Ni}, \mathrm{Ti}$ and $\mathrm{Cr}$. Most of the elements in the upper part of the graph are incompatible ones, in particular $\mathrm{Rb}, \mathrm{K}$, $\mathrm{U}, \mathrm{Cs}$, Th, Na and Al, all elements strongly incompatible in respect to iron. Vertical disposition of REEs is related to compatibility/incompatibility too: light REEs (La, Ce, Nd, $\mathrm{Sm})$, which within the REE are the most incompatible [26], are in the upper part of the graph, where PC2 is positive. Heavy REE (Eu, Tb, Tm, Yb, Lu) which show a less incompatible behavior than light REE, are found in the lower part of the graph, where PC2 is negative. Score plot of PC1 and PC2 (Fig. 4), where only samples with a

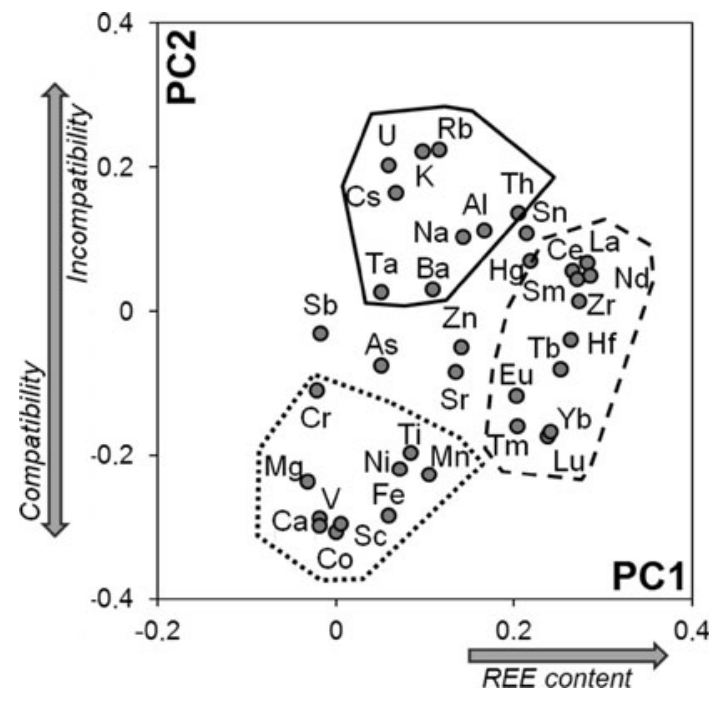

Fig. 3 Loading plot of the first and the second principal components. PC1 is related to rare earth elements (REE, dashed line): all the elements of this group occupy the right part of the graph, where PC1 is defined as positive. PC2 is related to compatibility/incompatibility of element: iron and elements with a similar geochemical behavior (compatible ones) are in the lower part of the graph (PC2 $<0$, dotted line), incompatible elements are in the upper part of the graph ( $\mathrm{PC} 2>0$, continuous line)

defined lithological composition are represented, underlines the differences between the various samples groups. In particular granitic regoliths are well separated by Ferrar ones which were produced directly by weathering of basalts and dolerites. The first ones occupy the upper part of the graph, revealing the presence of incompatible elements, the second ones are in the lower part, where PC2 gives importance to iron and compatible elements content. These features have a geochemical consistency, since granites are rich in incompatible elements, while basalt and dolerite are poor of them and rich in iron and compatible elements [27]. Other samples produced by weathering of Beacon sandstone and Priestley schist show an intermediate position between the 2 defined sample groups. This is in accordance to the genesis of these rock-types, which are composed by mixed fragment of pre-existing rocks. PC2 doesn't show a significative discriminating power among samples, since along $\mathrm{x}$-axis no sample differentiation can be noticed, therefore REE content can't be considered a good sample descriptor.

Since PCA revealed that REE and ICE are the most significative elements in order to characterize the samples, further observations were carried out for these elemental groups. REE profiles ( $\mathrm{La}, \mathrm{Ce}, \mathrm{Nd}, \mathrm{Sm}, \mathrm{Eu}, \mathrm{Tb}, \mathrm{Tm}, \mathrm{Yb}$ and $\mathrm{Lu}$ ) and ICE profiles (Cs, Rb, Ba, Th, U, V, Sc, Mn, Fe and $\mathrm{Mg}$, from the most incompatible element to the most compatible one) were prepared, using all the determined REE and a selection of compatible/incompatible elements, 


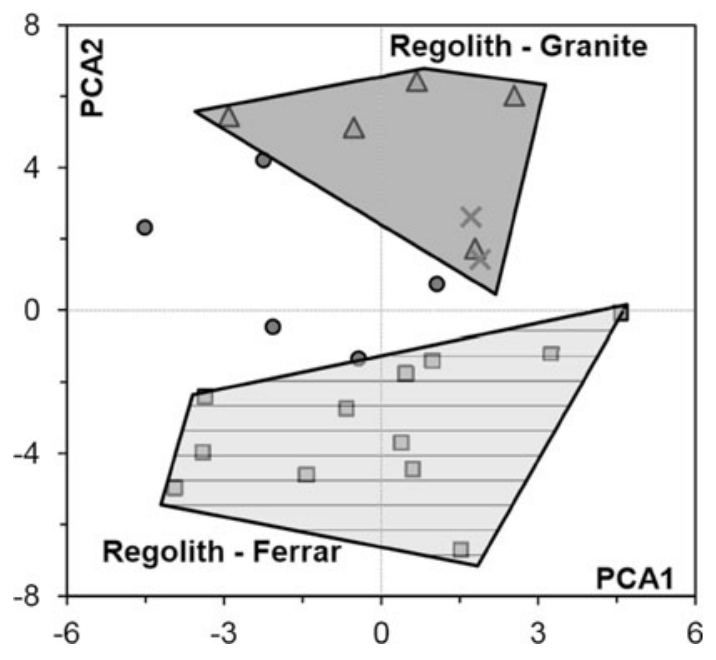

Fig. 4 Score plot of the first 2 principal components. Not all samples are represented, the ones reported are those whose lithological composition is known. Triangles represent granitic regoliths; squares represent regoliths produced by weathering of Ferrar rocks; circles represent regoliths produced by weathering of Beacon sandstone; crosses represent regoliths produced by weathering of Priestley schist. Two fields are showed: the one defined by granitic regoliths (upper part of the graph) and the one defined by Ferrar samples (lower part of the graph). The 2 fields are well separated along PC2, which is related to geochemical compatibility/incompatibility of elements; they are not discerned by PC1

considering the results of PCA; all concentrations were normalized to the upper continental crust mean average concentrations (UCC, data from [28]). In Fig. 5 are presented the profiles of the samples. Ferrar-regoliths and granite-regoliths show opposite behaviors (graphs a, b, c, d Fig. 5): Ferrar regoliths are enriched in heavy REE and compatible elements, granite-regoliths show high concentrations of light REE and incompatible elements, with the exception of $\mathrm{Ba}$, which is highly depleted if compared to the other incompatible elements. These features are in accordance with the geochemistry of granite and mafic rocks like the Ferrar ones. Comparing the profiles of the glacial sediments (graphs k, 1 Fig. 5) to the ones of Ferrarregoliths some similarities can be recognized: both show an enrichment in the heavy REE and in compatible elements and a depletion in light REE and in incompatible elements. Probably this reflects the composition of the glacial sediments, which is dominated by the presence of Ferrar rocks fragments. The identification of the main lithology in the composition of the Aeolian sediments (graph i, j Fig. 5) can't be carried out: the profiles are highly enriched in heavy REE (as the Ferrar-regoliths) and in incompatible elements (as the granite-regoliths). The irregular patterns characterizing these samples could be associated to a wellmixed composition, in accordance with their genesis. The 2 Priestley Schist-regoliths (graphs e, f Fig. 5) are generally enriched in REE and in very incompatible elements (Cs and $\mathrm{Rb}$ ), while significative features and evident patterns can't be found observing the Beacon sandstone-regoliths profiles (graphs g, h, Fig. 5). The two sands from coastal marine beaches and the mixed regolith doesn't exhibit significative variations in relation to the UCC mean concentrations, while this is the case of the lacustrine sand (graphs m, n, Fig. 5).

Some of the features recognized in the profiles can be associated to chemical weathering processes: Priestley Schist-regoliths and Aeolian sediments show an enrichment of REE in respect to the UCC and an Eu negative anomaly. These features could be related to the mobilization of the most mobile elements, which increase the relative abundance of REE in respect to the other elements [29, 30]; also the Eu anomaly could be explained by chemical processes affecting the samples [29]. Also the Ba negative anomaly which is observed in the Beacon sandstone-regoliths and in the Aeolian sediments could be an indication of chemical weathering [31].

\section{Conclusions}

Elemental composition, determined through INAA, of 40 samples of incoherent sediments $(\varnothing<1 \mathrm{~mm})$ collected from ice-free areas of Victoria Land (Antarctica) is presented. The determined elements range from major elements ( $\mathrm{Al}, \mathrm{Fe}, \mathrm{Ca}, \mathrm{K}, \mathrm{Na}, \mathrm{Mg}, \mathrm{Ti}$ and $\mathrm{Mn}$ ) to trace elements, including 9 of the 15 lanthanides. INAA proved to be one of the most powerful analytical technique for the determination of element concentrations in geological samples, allowing at the same time the determination of elements whose concentrations ranges from $10^{-1}$ to $10^{5} \mathrm{ppm}$.

The combined use of PCA and concentrations profiles allowed to recognize patterns, relationships and differences among the samples. In order to characterize and divide the samples, REE and ICE proved to be the most significative elemental groups. A first geochemical characterization focused the attention to these groups; it revealed some evidences for chemical weathering, specially related to the REE content. This is an important point since it is generally presumed that chemical weathering is not significative in cold and dry climate, as the Antarctic one, although products of chemical weathering are well documented both in soils in the Victoria Land [32-34] and in ancient glacial deposits [35]. Our geochemical evidences, which reveal an active and recent chemical alteration in the Victoria Land, confirm the incomplete and immature weathering processes at work in the Dry Valleys region, despite the extremely cold and dry climate [36]. Environmental and climatic condition of East Antarctica can be considered analog to Martian ones, for this reason the investigation of 


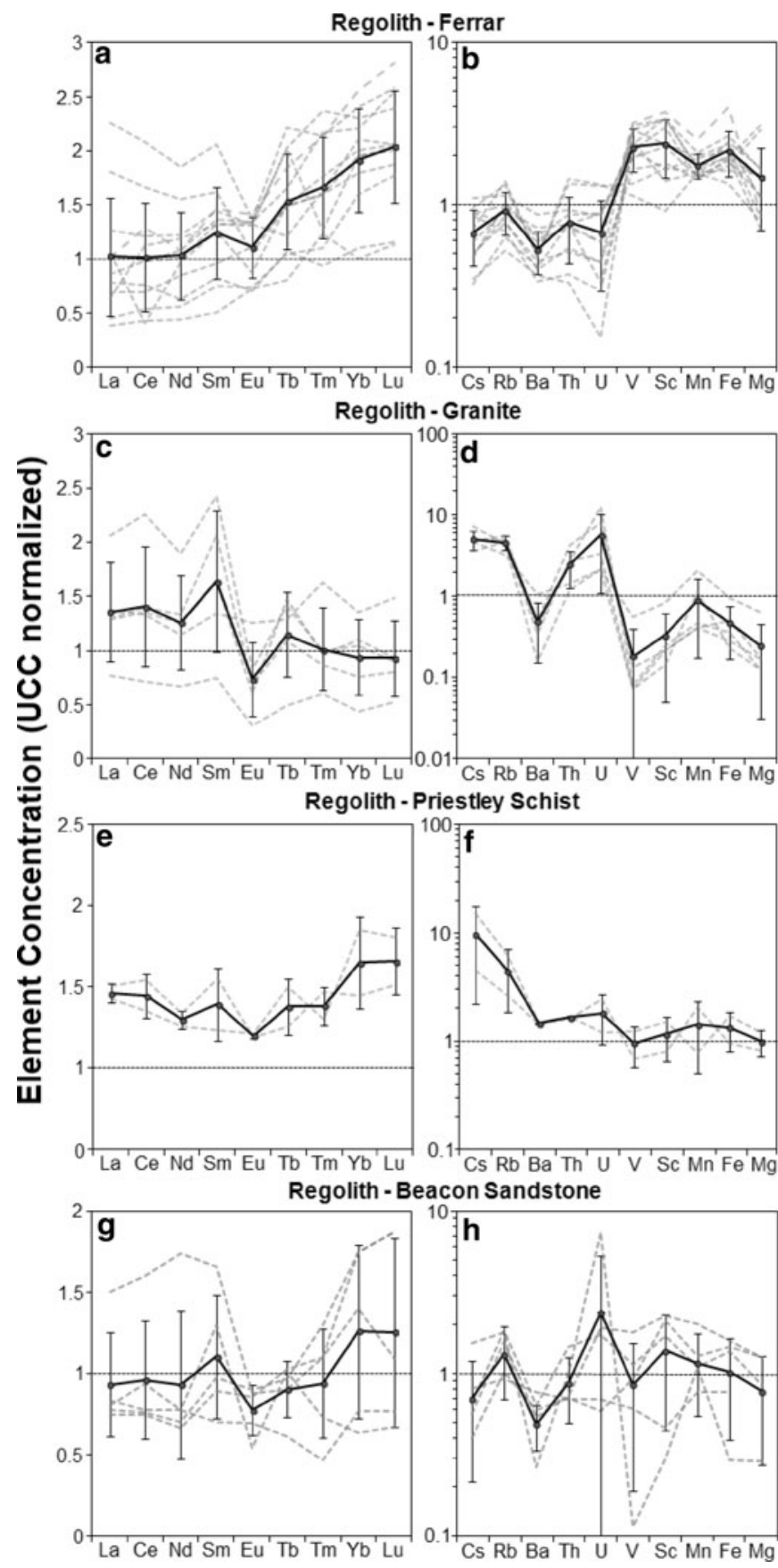

Fig. 5 REE and ICE profiles of the samples: on the left side the sample with a defined lithological composition are represented; on the right side samples with a mixed composition can be observed. The dashed grey lines represent the single samples, the black lines are the mean average profiles calculated for each group; the error bars associated to the average profiles are the standard deviations. For some mixed elements (graphs $\mathbf{m}$ and $\mathbf{n}$ ) the average profiles are not

weathering processes in Antarctica could be useful to investigate the dominant ones occurring on Mars [37].

Comparing the profiles it was also possible to identify the main lithological composition of some of the mixed sediments. Further analyses and observations are needed to
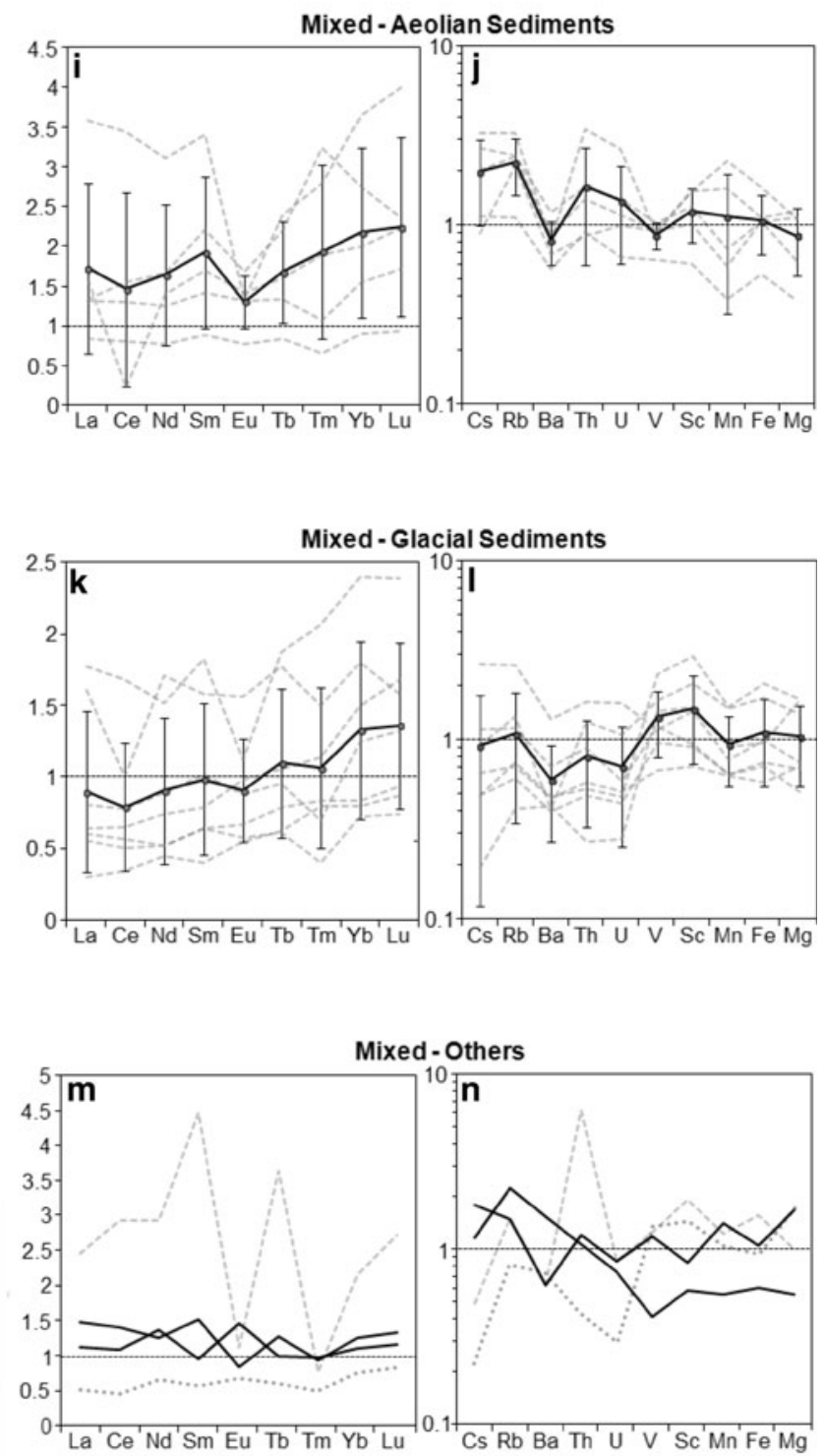

presented; in these graphs black lines represent the samples of sand collected from coastal marine beaches, the dotted line is associated to a mixed regolith with an undefined lithological composition, the dashed line is the profile of the lacustrine sand sample. The concentrations are normalized to the UCC mean average concentration (data from [28])

deeply investigate weathering processes in this region of Antarctica and to identify the active source areas of dust relatively to the Talos Dome area. To attain this goal it will be essential to determine the elemental composition of the dust entrapped in TALDICE improving a new specific 
analytical procedure. Another important point which should be investigated is the elemental grain-size dependent fractionation: this work was concerned on bulk sediments $(\varnothing<1 \mathrm{~mm})$; it would be interesting to determine the composition of the finer fraction of the sediments $(\varnothing<10-20 \mu \mathrm{m})$, which is the one actually deflated and transported by the wind to the Talos Dome area.

Acknowledgments Our sincere thanks to the Staff of the Laboratory of Nuclear Applied Energy (LENA) of the University of Pavia.

\section{References}

1. Maher BA, Prospero JM, Mackie D, Gaiero D, Hesse PP, Balkanski Y (2010) Global connections between aeolian dust, climate and ocean biogeochemistry at the present day and at the last glacial maximum. Earth Sci Rev 99:61-97

2. Lambert F, Delmonte B, Petit JR, Bigler M, Kaufmann PR, Hutterli MA, Stocker TF, Ruth U, Steffensen JP, Maggi V (2008) Dust-climate couplings over the past 800.000 years from the EPICA Dome C ice core. Nature 452:616-619

3. Petit JR, Jouzel RaynaudD, Barkov NI, Barnola JM, Basile I, Bender M, Chappellaz J, Davis M, Delaygue G, Delmotte V, Kotlyakov VM, Legrand M, Lipenkov VY, Lorius C, Pepin L, Ritz C, Saltzman E, Stievenard M (1999) Climate and atmospheric history of the past 420,000 years from the Vostok ice core, Antarctica. Nature 399:429-436

4. EPICA community members (2004) Eight glacial cycles from an Antarctic ice core. Nature 429:623-628

5. Yung YL, Lee T, Wang CH, Shieh YT (1996) Dust: a diagnostic of the hydrologic cycle during the last glacial maximum. Science 271:962-963

6. Grousset FE, Biscaye PE (2005) Tracing dust sources and transport patterns using $\mathrm{Sr}, \mathrm{Nd}$ and $\mathrm{Pb}$ isotopes. Chem Geol 222:149-167

7. Frezzotti M, Bitelli G, De Michelis P, Deponti A, Forieri A, Gandolfi S, Maggi V, Mancini F, Remy F, Tabacco I, Urbini S, Vittuari L, Zirizzotti A (2004) Geophysical survey at Talos Dome, East Antarctica: the search for a new deep-drilling site. Ann Glaciol 39:423-432

8. Delmonte B, Baroni C, Andersson PS, Shoberg H, Hansson M, Aciego S, Petit JR, Albani S, Mazzola C, Maggi V, Frezzotti M (2010) Aeolian dust in the Talos Dome ice core (East Antarctica, Pacific/Ross Sea sector): Victoria Land versus remote sources over the last two climatic cycle. J Quat Sci 25:1327-1337

9. Lanci L, Delmonte B (2013) Magnetic properties of aerosol dust in peripheral and inner Antarctic ice cores as a proxy for dust provenance. Global Planet Change. doi:http://dx.doi.org/10.1016/ j.gloplacha.2013.05.003

10. Albani S, Delmonte B, Maggi V, Baroni C, Petit JR, Stenni B, Mazzola C, Frezzotti M (2012) Interpreting last glacial to Holocene dust changes at Talos Dome (East Antarctica): implications for atmospheric variations from regional to hemispheric scales. Clim Past 8:741-750

11. Delmonte B, Baroni C, Andersson PS, Narcisi B, Salvatore MC, Petit JR, Scarchilli C, Frezzotti M, Albani S, Maggi V (2013) Modern and Holocene aeolian dust variability from Talos Dome (Northern Victoria Land) to the interior of the Antarctic ice sheet. Quat Sci Rev 64:76-89

12. Jenner GA, Longerich HP, Jackson SE, Fryer BJ (1990) ICPMS-a powerful tool for high-precision trace-element analysis in
Earth sciences: evidence from analysis of selected U.S.G.S. reference samples. Chem Geol 83:133-148

13. Benyaich F, Makhtari A, Torrisi L, Foti G (1997) PIXE and XRF comparison for applications to sediment analysis. Nucl Instrum Meth B 132:481-488

14. Madaro M, Moauro A (1987) Trace element determination in rocks and sediments by neutron activation analysis. J Radioanal Nucl Ch 114:337-343

15. Mahaney WC, Hancock RGV, Stalker AM (1994) Geochemical and physical analysis of the bedrock formations and lowest tills at the Wellsch Valley Site, Saskatchewan, Canada. J Radioanal Nucl Ch 180:5-13

16. Lara LBLS, Fernandes EAN, Oliveira H, Bacchi MA, Ferraz ESB (1997) Amazon estuary-assessment of trace elements in seabed sediments. J Radioanal Nucl Ch 216:279-284

17. Joron JL, Treuil M, Raimbault L (1997) Activation analysis as a geochemical tool: statement of its capabilities for geochemical trace element studies. J Radioanal Nucl Ch 216:23-229

18. Randle K, Al-Jundi J (2001) Instrumental neutron activation analysis (INAA) of estuarine sediments. J Radioanal Nucl Ch 249:361-367

19. Faure G, Mensing TM (2011) The Transantarctic Mountains: rocks, ice, meteorites and water. Springer, London

20. Greenberg RR, Bode P, De Nadai Fernades EA (2011) Neutron activation analysis: a primary method of measurement. Spectrochim Acta B 66:193-241

21. Nadkarni RA, Morrison GH (1978) Use of standard reference materials as multielement irradiation standards in neutron activation analysis. J Radioanal Nucl Ch 43:347-369

22. Borio di Tigliole A, Cammi A, Clemenza M, Memoli V, Pattavina L, Previtali E (2010) Benchmark evaluation of reactor critical parameters and neutron fluxes distributions at zero power for the TRIGA Mark II reactor of the University of Pavia using the Monte Carlo code MCNP. Prog Nucl Energy 52:494-502

23. Clemenza M, Fiorini E, Previtali E, Sala E (2012) Measurement of airborne 131I, 134Cs and 137Cs due to the Fukushima reactor incident in Milan (Italy). J Environ Radioactiv 114:113-118

24. Abdi H, Williams LJ (2010) Principal component analysis. Comput Stat 2:433-459

25. Faure G (1998) Principles and applications of geochemistry. Prentice Hall, New Jersey

26. Henderson P (1984) Rare earth element geochemistry. Elsevier, Amsterdam

27. Taylor SR, McLennan SM (1985) The continental crust: its composition and evolution. Blackwell Scientific Publications, Oxford

28. Rudnick RL, Gao S (2003) The composition of the continental crust. In: Rudnick RL (ed) The Crust, vol 3. Elsevier-Pergamon, Oxford, pp 1-64

29. Condie KC, Dengate J, Cullers RL (1995) Behavior of rare earth elements in a paleoweathering profile on granodiorite in the Front Range, Colorado, USA. Geochim Cosmochim Acta 59:279-294

30. Nesbitt HW, Markcovicz G (1997) Weathering of granodioritic crust, long-term storage of elements in weathering profiles, and petrogenesis of siliciclastic sediments. Geochim Cosmochim Acta 61:1653-1670

31. Price RG, Gray CM, Wilson RE, Frey FA, Taylor SR (1991) The effects of weathering on rare-earth element, $\mathrm{Y}$ and $\mathrm{Ba}$ abundances in Tertiary basalts from southeastern Australia. Chem Geol 93:245-265

32. Campbell IB, Claridge CGC (1987) Antarctica: soils, weathering processes and environment. Elsevier, Amsterdam

33. Ugolini FC, Bockheim JG (2008) Antarctic soils and soil formation in a changing environment: a review. Geoderma 144:1-8

34. Bockheim JG (2013) Soil formation in the Transantarctic Mountains from the Middle Paleozoic to the Antropochene. Palaeogeogr Palaeocl 381-382:10-98 
35. Baroni C, Fasano F, Giorgetti G, Salvatore MC, Ribecai C (2008) The Ricker Hills Tillite provides evidence of Oligocene warmbased glaciation in Victoria Land, Antarctica. Glob Planet Chang 60:457-470

36. Salvatore MR, Mustard JF, Head JW, Cooper RF, Marchant DR, Wyatt MB (2013) Development of alteration rinds by oxidative weathering processes in Beacon Valley, Antarctica, and implications for Mars. Geochim Cosmochim Ac 115:137-161

37. Marchant DR, Head WH (2007) Antarctic dry valleys: microclimate zonation, variable geomorphic processes, and implications for assessing climate change on Mars. Icarus 192:187-222 